\section{Brain-derived neurotrophic factor as biomarker}

To the Editor,

The publication on "Prognostic significance of brain-derived neurotrophic factor (BDNF) levels in patients with heart failure and reduced left ventricular ejection fraction" is very interesting (1). Barman et al. (1) concluded that decreased serum BDNF levels were associated with death and rehospitalization in patients with $\mathrm{HF}$, suggesting their usefulness as prognostic biomarkers. As commented in the editorial, concurrent medical disorders can alter the clinical significance of BDNF (2). Nevertheless, there are other concerning factors regarding the usefulness of BDNF as a biomarker. For example, in laboratory medicine, poor reproducibility of the BDNF assay is common, which limits its usefulness as a biomarker (3). In addition, the conditions of blood sample collection and processing can significantly affect the BDNF levels (4). As reported by Tsuchimine et al. (5), anticoagulant compounds as well as the storage time and temperature during blood sampling can affect the measurements of plasma BDNF levels.

\section{(D) Pathum Sookaromdee, (D) Viroj Wiwanitkit' \\ TWS Medical Center; Bangkok-Thailand \\ 'Dr. DY Patil University; Pune-India}

\section{References}

1. Barman HA, Şahin I, Atıcı A, Durmaz E, Yurtseven E, Ikitimur B, et al. Prognostic significance of brain-derived neurotrophic factor levels in patients with heart failure and reduced left ventricular ejection fraction. Anatol J Cardiol 2019; 22: 309-16. [CrossRef]

2. Yılmaz MB. Brain-derived neurotrophic factor in heart failure. Anatol J Cardiol 2019; 22: 317-8. [CrossRef]

3. Polacchini A, Metelli G, Francavilla R, Baj G, Florean M, Mascaretti $L G$, et al. A method for reproducible measurements of serum BDNF: comparison of the performance of six commercial assays. Sci Rep 2015; 5: 17989. [CrossRef]

4. Pareja-Galeano H, Alis R, Sanchis-Gomar F, Cabo H, Cortell-Ballester J, Gomez-Cabrera MC, et al. Methodological considerations to determine the effect of exercise on brain-derived neurotrophic factor levels. Clin Biochem 2015; 48: 162-6. [CrossRef]

5. Tsuchimine S, Sugawara N, Ishioka M, Yasui-Furukori N. Preanalysis storage conditions influence the measurement of brain-derived neurotrophic factor levels in peripheral blood. Neuropsychobiology 2014; 69: 83-8. [CrossRef]

Address for Correspondence: Pathum Sookaromdee, MD, TWS Medical Center,

Bangkok-Thailand

Phone: 6624788963

E-mail: pathumsook@gmail.com

CCopyright 2020 by Turkish Society of Cardiology - Available online at www.anatoljcardiol.com

DOI:10.14744/AnatolJCardiol.2020.84699

\section{Author`s Reply}

To the Editor,

We would like to thank the author(s) for their interest and valuable comments on our manuscript entitled "Prognostic significance of brain-derived neurotrophic factor (BDNF) levels in patients with heart failure and reduced left ventricular ejection fraction" (1). In the authors' letter to the editor, the authors mentioned that there are potential concerns regarding the usefulness of BDNF as a biomarker.

The main aim of our study (1) was to investigate the relationship between BDNF levels in patients with heart failure (HF) and reduced left ventricular ejection fraction (LVEF), considering death or rehospitalization due to HF. Several recent studies have shown the association of BDNF with cardiovascular diseases. The prognostic significance of BDNF has been demonstrated in patients with hypertension, $\mathrm{HF}$, and coronary artery disease (CAD) $(2,3)$. Because antidepressant medications can affect BDNF levels, patients with a history of a psychiatric disorder, such as major depressive disorder, schizophrenic disorder, or organic brain disorders, were excluded from our study. Like other studies that investigated the relationship between BDNF and heart failure (3-5), we measured BDNF levels using ELISA. Since BDNF is released from many tissues, such as brain, heart, endothelial, and skeletal muscle (6), it is unknown which organ decreases BDNF levels in patientswith HF the most. It is believed that the mean serum BDNF levels are 100-fold higher than plasma levels because of platelet degranulation during the coagulation process (7). Because the majority of circulating BDNF is stored in platelets, it has been shown in the literature that the amount of BDNF in serum is similar to that in washed platelet lysates (8). Reliable biomarkers for diagnosis, treatment followup, and prognosis remain an unmet medical requirement. There is a consensus that BDNF can be an important measurable biomarker. However, future studies are needed to provide the basis for obtaining optimal BDNF measurements suitable for future clinical trials using human serum.

Hasan Ali Barman, (1) Irfan Şahin', (1) Adem Atıcı'2, (1) Eser Durmaz', Ece Yurtseven4, (-) Barış İkitimur33, (1) Ertuğrul Okuyan',

Ibrahim Keleş ${ }^{3}$

Department of Cardiology, 0kmeydanı Training and Research Hospital; Istanbul-Turkey

'Department of Cardiology, Bağcılar Training and Research Hospital; İstanbul-Turkey

${ }^{2}$ Department of Cardiology, İstanbul Gaziosmanpaşa Taksim Training and Research Hospital; İstanbul-Turkey

${ }^{3}$ Department of Cardiology, Cerrahpașa Faculty of Medicine, İstanbul University; İstanbul-Turkey

${ }^{4}$ Department of Cardiology, Faculty of Medicine, Koç University Hospital; Istanbul-Turkey 